Western Washington University Western CEDAR

2008

\title{
Thinking Critically about Difference: Analytical Tools for the 21st Century
}

Margaret Zamudio

Francisco Rios

Western Washington Unviersity, francisco.rios@wwu.edu

Angela M. Jaime

Follow this and additional works at: https://cedar.wwu.edu/woodring_dei

Part of the Education Commons

\section{Recommended Citation}

Margaret Zamudio, Francisco Rios \& Angela M. Jaime (2008) Thinking Critically about Difference: Analytical Tools for the 21st Century, Equity \& Excellence in Education, 41:2, 215-229, DOI: 10.1080/ 10665680801957378

This Article is brought to you for free and open access by the Woodring College of Education at Western CEDAR. It has been accepted for inclusion in Woodring Scholarship on Diversity, Equity, \& Inclusion by an authorized administrator of Western CEDAR. For more information, please contact westerncedar@wwu.edu. 


\title{
Thinking Critically about Difference: Analytical Tools for the 21st Century
}

\author{
Margaret Zamudio, Francisco Rios, and Angela M. Jaime \\ University of Wyoming
}

\begin{abstract}
This article examines a critical cultural thinking framework advanced to develop an analysis of difference as it pertains to race, gender, and sexuality. We examine student journals to document their use (or lack therein) of these critical cultural thinking concepts and how these concepts influence students' understanding of difference. While there are a number of tools that students can rely on for thinking critically, we advance four concepts that are central for the development of a critical cultural consciousness. ${ }^{1}$ The critical cultural thinking skills we identify in this article are (1) organic experience, (2) relational analysis, (3) historical analysis, and (4) conception of power relations. We argue that these tools are central for an intellectual understanding of difference. As the student journals analyzed in this article demonstrate, in the absence of these tools of inquiry, much of the campus discourse reverts to oppressive frameworks, which not only serve to oppress students of color, women, and gay and lesbian students but also erodes the practice of citizenship that is crucial for the development of educational democracy.
\end{abstract}

\section{CITIZENSHIP AND DEMOCRACY}

We see critical cultural consciousness as central to active and engaged democratic citizenry aspiring to a social justice ideal (McLaren, 2003). It is in the educational setting that we often learn to be citizens (Parker, 2003). It is in this setting where we either learn to include or excludeto appreciate and embrace, or to subordinate difference. Theories of learning have tended to focus on the behaviors of individuals in controlled settings (i.e., behaviorism) (Skinner, 2002) or, more recently, on the inner workings of the mind (i.e., information processing) (Anderson, 2004); we have become equally aware of the social nature (Moll, Amanti, Neff, \& Gonzalez, 1992; Vygotsky, 1980) as well as the political nature of learning (Freire, 1998; McLaren, 2000; Shor \& Pari, 2000).

With respect to the political nature of learning, we have come to see how education has served as a mechanism in the ideological colonization of groups of people (Springs, 2003). In this regard, schools have historically been used as socializing agents where "deculturalizing" processes were widespread. At the university level this process continues as debates about affirmative action, struggles over the support for ethnic studies programs, and superficial attempts 
to "do" diversity imply the widespread support for the continued marginality or erasure of the Other. Montoya (1998) posits that even in higher education, "academic success traditionally has required that one exhibit the linguistic and cognitive characteristics of the dominant culture" (p. 438).

But we also have seen how education within a critical multicultural framework can be a liberating process. Consider the sugar cane workers in Brazil who came to see literacy as an emancipatory process (Freire, 1970/1998). Consider the vital role the Highlander School played in preparing people to assume leadership positions in the Civil Rights Movement (Horton, 1989). Consider the new "freedom writers" and the work of their teacher who helped these young people to develop as active, democratic citizens while simultaneously learning the skills that would move them through graduation and into college (Gruwell, 1999).

The university also is a setting for both deculturalization and liberation. We argue that it is at the university (primarily through ethnic and women's studies classes) where minority students often come to understand the historical context underlying life-long feelings of exclusion. These same students are often challenged to put their education into practice, to empower themselves through critical education and action (praxis). But it is also at the university where white students are urged (at least in most university mission statements (see VanDeventer Iverson, 2007) to affirm diversity, negotiate international perspectives, and question parochial perspectives. Indeed, McLaren (2003) states, "schooling must be partisan. That is, it must be fundamentally tied to a struggle for a qualitatively better life for all through the construction of a society based on nonexploitative relations and social justice" (p. 70). Thus, the potential for liberation always exists when students are encouraged to step outside of their individual world, to develop empathy, to think historically, and to think critically.

Both of these liberating and colonizing ideologies, policies, practices, and pedagogies are evident in schools and college classrooms and serve as "tension and contradiction" within these institutions (Trent et al., 2003). McLaren (2003) explains that we should view "the school not simply as an arena of indoctrination or socialization or a site of instruction, but also as a cultural terrain that promotes student empowerment and self-transformation" (p. 70). Interestingly, then, we have come to understand the irony, the contradiction, and the profound challenge of moving educational institutions from agents of oppression to agents in service of liberation. We then add to this mix the prevailing political and cultural winds of the nation-state that gives strength to one or the other of these tensions. What becomes critical, then, is how schools and universities negotiate these tensions and these political winds within the context of stated institutional missions and values.

Feagin and Feagin (1986), Freire (1973), and Scheurich and Young (1997) have developed critical cultural consciousness paradigms that have informed the curriculum around the consideration of the experiences of oppressed groups. Within each of these paradigms, all students are encouraged to see inequality as part of broader (not individual) processes. More privileged students also experience a sense of discomfort as they develop intellectually and see how their own privilege is socially constructed (McIntosh, 1990). The intended goal of a critical education is to create a democratic citizenry committed not only to helping to resolve important social issues, but also to think deeply about the factors that create those dilemmas (what social and institutional factors contribute to these problems, which groups stand to gain from them, which groups lose, how these dilemmas keep us from the promise of a true democracy, etc.) (Westheimer \& Kahne, 2004). In order to do so, we argue that students need tools that permit them "to examine the 
underlying political, social and economic foundations of the larger society" (McLaren, 2003, p. 72).

\section{CRITICAL CULTURAL THINKING TOOLS}

We assert that a comprehensive ethic of inquiry, with respect to issues related to difference and inequality, would involve consideration of at least four conceptual tools. Although we do not argue that these four elements are all-inclusive when considering issues of race and racism, sexism, and exploitation, we believe they serve as a helpful (initial) framework for spurring a habit of critical cultural thinking in students. Importantly, each of these conceptual tools for understanding (and teaching) can be found in the work of radical educators (Darder, 2002; Feagin \& Feagin, 1986; Scheurich \& Young, 1996). Throughout Paulo Freire's work (1970/1998, 1973, 1985; see also, Darder, 2002), he develops the importance of a variety of critical thinking elements within a critical pedagogy.

Our reconceptualization of these tools developed in the process of analyzing data drawn from student journals for a project that demonstrated the link between the liberal discourse of colorblindness and traditional racist assumptions (see Zamudio \& Rios, 2006). The absence of critical thought demonstrated in the journals in some instances and expressed in other instances struck us as worthy of examination. The question we then asked was: What conceptual tools did students either possess or lack when analyzing difference? In a recursive process using the work of the critical theorists that see the possibility of education as emancipatory (Darder, 2002; Freire 1998; McLaren, 2003) as well as our own work grounded within students' actual journal descriptions (Zamudio \& Rios, 2006), we drew out four key pedagogical constructs and developed a conceptual understanding for each. We briefly summarize the conceptualization of these key concepts below. We then detail the context of this study and provide an in-depth description of each construct connected to students' journal entries to argue that the presence or absence of these conceptual tools makes a difference in the ability of students to see the underlying processes that structure inequality. Armed with this insight, we believe students will be better prepared to use education to think more critically and, in doing so, support movement toward a more just society.

The notion of "organic experiences" makes up our first conceptual tool and asserts that the students' lived reality provides them with insight into fundamental truths about inequality in society. The "truths" in this sense refer to the knowledge that is created through lived experiences, rather than the knowledge given to us in the form of dominant ideology. It is through lived experiences that cultural forms of subordination and domination are evidenced and interpreted. Organic experiences provide the text to interrogate the authenticity of ideas. In this case, one's life text can be used to challenge racism, sexism, and exploitation. To supply a student with the tool of organic experience "means that such experiences in their varied forms have to be recovered critically in order to reveal both their strengths and weaknesses" (Freire 1985, p. xxii). Students who do the work of critically recovering their experiences and testing them against how well these ideas inform their lives are better skilled in translating their knowledge to capture the experiences of the Other. Thus, organic experience as a tool helps students to decipher the dominant ideologies that create conditions of oppression.

Likewise, "relational analysis," as a critical cultural thinking tool, allows for students to make deep connections between their lives and the lives of others and the social world. Relational 
analysis makes the connection between individuals and structures of oppression. In this way, students start to see how structures like class, race, gender, and sexuality shape people's experiences. It also helps students understand how their ideas and actions feed existing structures of domination. Conversely, relational analysis also empowers students to take positions and actions that help transform these structures. Ultimately, relational analysis makes education an active tool for social transformation not only of the self but also of society. What students do and say matters.

Relational analysis is also an exercise in "historical analysis." While understanding history does not change historical facts, it provides students with a contextual analysis to understand how historical structures produce contemporary forms of inequality. Historical analysis provides students with a tool to make connections between the past and present. Henry Giroux (1985) writes of the centrality of historical analysis for a critical education:

Freire believes that a critical sensibility is an extension of an historical sensibility. That is, to understand the present, in both institutional and social terms, educators must place all pedagogical contexts in an historical context in order to see clearly their genesis and development. (p. xxiv)

Rounding out the critical cultural thinking toolbox is the consideration of the impact of "power relations" in defining difference and determining inequality. An analysis of power ultimately recognizes that power is embedded in all social relationships. From those encountered at the level of organic experiences to those historically given, social relationships reflect existing power relationships. Students who conduct an analysis of power are better prepared to critique and act against racist and sexist ideologies that serve to subordinate oppressed groups. For example, Peter McLaren (2003) calls this form of analysis "emancipatory" and argues:

Emancipatory knowledge helps us understand how social relationships are distorted and manipulated by relations of power and privilege. It also aims at creating the conditions under which irrationality, domination, and oppression can be overcome and transformed through deliberative, collective action. In short, it creates the foundation for social justice, equality, and empowerment. (p. 73)

We assert that these four conceptual tools associated with a habit of inquiry when considering issues of difference are essential for more authentically understanding inequality. To be sure, these conceptual elements overlap; we separate them out strictly for instructional purposes. Further, we note that different postures can be taken related to the foci and depth for each element. The data we analyzed suggest that the degree to which students rely on these critical thinking elements, differs. Our data show that some do not account for these epistemological elements in the slightest, while others use them to gain profound insight of the inequality around them.

To be sure, the degree to which our students consider and provide critiques of social inequality using these elements is dependent on many things, including their own experiences (organic), their movement from an individualistic to a structural view of the world (relational), the degree to which these conditions for understanding have been made available to them (historical), and the ways in which forces of privilege undermine these (power). Indeed, it is our contention that schools, including (and perhaps most especially) institutions of higher education, have a special obligation to promote a habit of critical cultural inquiry via our curriculum, pedagogy, and institutional supports. In a society where the structures of inequality challenge the democratic 
ideal, only the development of a critically culturally informed citizenry can move us away from the contradictions that exist in society. As the data and analysis that we present below suggest, students who use the tools for a critical cultural understanding in society demonstrate the habits of citizenship.

\section{METHODOLOGY: DATA COLLECTION AND ANALYSIS}

\section{Context}

The study took place at a university located in a sparsely populated state in the mountain west. The state is largely monocultural with less than $12 \%$ of its citizens coming from ethnic minority backgrounds. The student body is a reflection of the state on several levels: Most students come from the state, from rural communities, and from conservative backgrounds. The diversity of the student body also mirrors the state; students of color comprise about $9 \%$ of the 12,000 students who attend. Despite this homogeneity, the university has sought to make diversity and internationalization a significant area for discussion, planning, and development (University Academic Plan, 2004).

\section{Data Collection and Analysis}

We draw our sample from the journals of students enrolled in Social Problems, an undergraduate sociology course cross-listed with Women Studies and Chicana/o Studies, and from an upper division/graduate course titled U.S. Women of Color. The project was originally part of a national study by Joe Feagin and Leslie Houts. One of their goals was to document the national atmosphere of racism on college campuses. The data for the project were collected in these classes from the fall of 2002 through the fall semester 2003. Involvement in the project was voluntary but participants received extra credit.

Students were instructed to keep a journal in which they would write descriptions of situations that involved race, gender, and sexuality. The situation could be anything: from the interaction between a mixed-race group, conversations overheard in a local store or supermarket, or personal conversations. Initially, students were asked not to analyze what they thought of the situation but only to document it. Despite these instructions, at least two-thirds of the initial student sample could not resist documenting their responses to their observations. These unsolicited commentaries proved fortuitous in understanding the status of basic critical cultural thinking elements in the students' analysis of difference. The assignment yielded over 100 journals and over 1,000 journal entries.

Data were analyzed using a grounded theory (Strauss \& Corbin, 1998) approach. In our role as graduate faculty and researchers, we looked at excerpts from the students' journals and asked ourselves what themes were evident in the thinking exemplified in the students' writing and what do these excerpts suggest students are missing. We considered existing conceptual frameworks (described earlier), created the four categories, and then returned to the data in search of exemplars. We used each other for clarification and challenge to arrive at more robust understandings of how these elements play out in students' thinking. 
We now turn to the analysis of the four elements central to a critical cultural framework as they appear (or fail to appear) in the intellectual toolbox that these students draw on to make sense of issues of difference, particularly as they relate to race. While we focus on race throughout our analysis, we also include examples of students' attempts to make sense of sexuality and gender. Whereas the antecedents for the construction of the social categories of race, sex, and sexuality may differ, we posit that students need the same analytical tools to understand and deconstruct the oppressive nature of social injustice.

We provide examples from the students' journals that serve to highlight the operation of each element either as a positive or a negative instance of critical cultural thinking. We share these to bring life to each of these elements.

\section{THINKING ABOUT DIFFERENCE}

\section{Organic Experience}

Often, an organic view develops within either a framework of empathy (for the dominant groups) or oppression (for subordinated groups). The oppressed experience the contradictions in the dominant discourse and are often the first to point out these contradictions. The understanding that comes from one's organic experiences is captured in the journal of a 20-year-old Native American woman:

I was at a party at some friends' house ... One of my friends came up to me and whispered, "There is a black guy here." I said to her, "So?" It turned out that the guy was Hispanic. I could tell he was Hispanic the first time I saw him. I ended up talking to the guy for quite a while, and I really enjoyed his company. It bothered me that everyone was talking about him before actually meeting him.

From the journal entry we can glean the extent that one's own experience as the Other helps to understand how racial categories de-individualize racial minorities and her aim to treat the young man as a human and to offset the assumptions of the other students.

The foundation for developing an organically oriented critical view of the world apparently stems from her experiences on and (most especially) off the reservation. The same student wrote:

I was talking to my younger cousin ... a junior in high school. She goes to the same school that I went to, which is on the reservation. She asked me if I took Biology II and if we had to go look at the cadavers. I had done the same. She asked me if people there were mean. I said, "Yes." The town that they went to is off the reservation. She told me that a girl from a different school came up to her and told her that they didn't like brown dogs around there. My cousin stuck up for herself the best she could without causing any problems. Things like this happen regularly off the reservation. I never personally experienced it because I do not look very Indian, but I have been with friends when similar situations have occurred. It makes me very angry that people are still prejudice against people just because they are a different race.

By developing capacity for empathy, those who do not experience the contradiction first hand are able to understand how social "conventions" can have a harmful impact on some people. A 
20 -year-old, white female exemplifies the ability to use empathy as a means of understanding the experiences of others. In an early entry, she acknowledges:

I have never been denied a thing in my life ... I can have an open mind and open my eyes to the world's reality, and not see the world through rose-colored glasses. I can do my best to be empathetic to others.

This student demonstrates the organic element of a critical paradigm by understanding her privileged position. In another entry she shows how empathy for the experience of others narrows the ideological chasm between herself and others:

I work as a waitress at the restaurant . . . a typical diner like atmosphere ... There is one employee ... who gets some negative attention from the coffee counter good ole boys. This is a man I'm going to call Ray. Ray is gay. Ray refuses to wait on these men. These men give Ray the reason to be scared for being openly homosexual ... One man who sits at the counter from time to time openly said the words "fucking faggots" in Ray's direction. He never said it directly to Ray, but I caught all of it. I was blown away, the look in his eye toward Ray of pure hate, the intimidation he wished to have over Ray. I felt like the words were directed at me, and I wanted to explode, I could have, probably should have. He knew I heard him. ... In that moment I knew why gays feared for their lives because of attitudes like the good ole boys that are present. Here in Wyoming these attitudes are far too common.

This awareness of positionality and privilege, coupled with a developed sense of empathy, gives her the tools to intellectually and emotionally decipher the irrationality of hate in the words and deeds of the "good ole boys." This deeper analysis allows her to understand and be outraged by the fear that Ray experiences. This student has done the preliminary analytical work for a greater understanding of society and the responsibilities placed on individuals required to maintain a civil democracy.

When students fail to draw on the intellectual tools of the organic experience we see not only the frustration in their thought processes but also a social immaturity that threatens the principles of civil society. This example comes from the observation of a 22 -year-old, white, female graduate student. She wrote:

I recently met with a student in my class about her potential paper topic. ... She came out and told me she was a lesbian, and this had prompted her research in this area. She then proceeded to tell me about her coming out situation and how it has changed her life. . . The girl is also a student in my boyfriend's class. I told him that this particular student had come out to me at our meeting. He suddenly got really frustrated and blurted out, "Why do people who are gay have to continually come out and say that? I don't go around telling people that I sleep with girls." I didn't really have an answer. I knew he was frustrated and is an admitted homophobe. We were silent the rest of the way home, but you could tell he was fuming over this question.

The absence of an organic experience to draw upon shapes a very different understanding of the Other when compared to the more critical response of the student analyzing "Ray's" situation. The commentator, herself, is left speechless. Yet if this couple had drawn on their organic experience of privilege, neither the frustration, nor lack of answers, would have arisen. In our society where heterosexuality is privileged there is no need to announce one's preference with the hope of 
gaining acceptance; heterosexuality is given. In this situation, empathy for the experiences of others would have broadened their understanding of the student "coming out."

\section{Relational Element}

Without a relational analysis of the world, racialized discourses seem benign and unconnected to existing inequalities. Students fail to make this connection and often couch racist remarks as merely "kidding around" with very little understanding that these off color remarks are, in fact, quite harmful. A 21-year-old, white female wrote:

I was eating at Taco Johns and two guys came and ordered their food and sat down behind me. One guy continued what must have been a previous conversation by saying "Hey I'm not a racist, I own colored TV." I admittedly laughed at the joke and went on eating my food.

The journals are littered with "jokes" and derogatory terms mostly directed at people of color. While it is not surprising that this discourse exists on a university campus, it is disturbing that students fail to make the connection between these everyday (seemingly benign) interactions and greater inequalities in society. The failure to make this connection and therefore to "innocently" perpetuate racism, stems from students' lack of a relational analysis between social forms. We argue that race-based humor is rooted in larger structures of oppression with social and political meaning beyond the conscious or unconscious intentions of the actors involved. It is likely that many of the students who make these remarks do not intend any harm. But the point of a relational analysis is to document how even unintentional behavior has consequences far greater than the immediate contextual situation. The absence of this understanding further erodes a civil discourse when students excuse even blatant traditional forms of racism by reasoning that the person was just kidding (and therefore not a racist).

In comparison, students who are developing critical cultural analytical skills are very aware that humor has social and political implications. They understand racism and how it can be satirically used to make a political and social point. One of these students, a white female in her twenties, captured the relational analysis underlying humor. Her journal stated:

While we were all surfing the net, Jason showed me a website he discovered. It is www.blackpeopleloveus.com. It is hilarious. The whole thing is set up as this white couple that have posted pictures on their site of themselves with all of their black friends. The couple is dressed as typical yuppies with sweaters around their necks and well-coifed hair. Each picture is accompanied by a satirical little testimonial from the black friends about the greatness of the white couple. They go on to say how much they love their black friends and are "down" with them. It's really funny and satirical and a great idea for exposing the ridiculousness of stereotypes.

A critical cultural analysis gives this student an edge as a thoughtful participant in a civil democratic society. It might be helpful to understand that throughout her journal she discusses and confronts her own racism and stereotypes. She documents actions and attempts to form coalitions with oppressed groups. Drawing on an analysis of organic experiences of privilege and oppression, she attempts to make sense of her efforts when they fail. It is clear that this particular 
student is engaged in the process of critical cultural analysis, and one aspect of this analysis is an understanding underlying social relationships in words and deeds.

Another aspect of a relational analysis concerns not only the relationship between ideas and words to broader social structures but also the relationship between the individual and society. The dominant ideology within the U.S. society honors individualism as "sacred" combined with the belief in meritocracy without consideration for how social relations constrain the individual (Villenueva, 1993). We assert that each of us is powerfully influenced by the social categories to which we belong and by the individuals with whom we are connected. Ultimately, a relational understanding of the world undermines an ideology of pure individualism and encourages students to think beyond simplistic "bootstrap" theories.

The journal of a white, 19-year-old female is instructive. In one entry she reflected on the following condition: "Today I noticed that there are no blacks in any of my classes but one. I wonder why there are so few of them here at the university." Indeed, African Americans are underrepresented at universities across the nation, and various explanations have been proffered to account for this situation. Most of these explanations focus on deficit models and problems with the culture of minority communities that tend to hold them back, while few of these theories focus on the connection between individuals and the social context that either facilitates or undermines educational outcomes. Emphasis on deficit models provides part of the "seamless ideological web" of misconceptions (Weiner, 2000, p. 381) that gives primacy to individual culture rather than social structural forces (Steinberg, 1989; Weiner, 2000). In these views, lower educational attainments of those within minority communities stem from their aberrant values, an anti-intellectual culture that does not value education. For example, the notion of a culture of poverty (Payne, 2005), commonly invoked to explain continued racial inequality, places the blame of educational failures on the minorities themselves, whereas a relational analysis gives students an understanding that individuals do not operate in a vacuum. Consider the following entry (which was preceded by two other examples of racial conflict at the university) from the same 19-year-old female who wondered why there were so few black students at the university:

Today I was in my room and one of the girls on my floor stopped by. She was from a different state so I asked her why come to this university? And she said ... "The colleges where I am from are too expensive, except one and it is the second-generation wetback capitol. So I couldn't go there."

If this student had developed a relational analysis from within her very own journal entries, she would have been able to start answering the question of why there are so few students of color at this university. And part of her answer would consider the relationship between the racist acts she documents at the university.

The development of a relational analysis provides a foundation to reflect on the social condition as it applies to all students. In contrast to students who merely observe the world with fewer tools to explain the negative aspects of society, a student with a relational analysis is further along the road in understanding injustice. In the following entry a student relied on her advanced analytical tools to understand why a black friend refused to drive through her neighborhood to meet her mom:

In class today, a black male student shared the story of how he drives a pretty nice truck around town. He says that it never fails but there is a cop who is out to get him and pulls him over ... This makes 
me think about how lucky I am to never have experienced any sort of racial discrimination at the hands of law enforcement - people who are supposed to fairly look out for the welfare of citizens, not harass them. Then I thought about the time, back when I lived in Cleveland, that my friend and I were driving back to school after getting some dinner. He was an extremely large, heavy, black man. He was driving, and I suggested stopping quickly at my mom's house so that she could meet him.... We were very close to my home suburb, but my friend, Michael, completely refused to drive through the town at all. Parma is a bit notorious for having an overwhelmingly white population and not being friendly to black people who move in to the neighborhoods (exemplified by the cross burnings that have happened on people's lawns). Michael maintained that while he would have liked to meet my mom, there was no way he was going to be seen driving through Parma with a little, white girl in the seat next to him. He was afraid the cops would think he kidnapped me. I laughed at him then, but I understand completely where he was coming from and how legitimate his fear was.

This student is using several tools at once. She considers the organic experience of others while reflecting on her own relative privilege. She can readily explain the absence of a particular group in her community without resorting to a cultural deficit model for an explanation. In this view, there is nothing wrong with Michael; the community context prevents him from doing what white people take for granted (i.e., driving through a neighborhood, attending a safe school, etc.). This situation is not much different from how many students of color respond when they find themselves alienated at the University. They leave or fail to attend altogether because of the obstacles they encounter while negotiating the social context of the system, obstacles not readily apparent to students who lack the tools to help decipher their observations.

\section{Historical Element}

The journal entry of an 18-year-old Chicana student suggests how the illusion of a colorblind society makes it difficult for other students to understand the impact of history on the lives of people of color:

One of the topics that had been discussed in class was if ... minorities should be granted scholarships. ... The girl from class was complaining to her friend because she thought money was being taken away from others. She felt that minorities should be classified in the same category as Whites.

The notion that historically oppressed people should be treated in the same way as Whites when it comes to university admissions and scholarships, at face value, upholds democratic principles of equality. However, the insistence on "equal opportunity" in the absence of a historical perspective of how inequality has been historically structured and remains embedded in society serves to perpetuate that inequality. Bonilla-Silva (2003) uses interviews to delineate the concept of colorblind racism, pointing out that most Whites "ignored the effects of past and contemporary discrimination on the social, economic, and educational status of minorities. Therefore, by supporting equal opportunity for everyone without a concern for the savage inequalities between whites and blacks ... safeguards white privilege" (p. 31).

For students lacking historical perspective, the past has no effect on the present. Moreover, the types of racial harassment and discrimination commonly associated with the ideology of traditional forms of racism is no longer thought to play a role in the experiences of students of 
color. But that historical (racist) ideology lives. An 18-year-old, black, male student documented the racial ideology that permeates his present environment:

I was in the cafeteria when these two Caucasian guys were ... talking about "Man we have too many black kids at this school now. What is up with that? They're only here for sports anyways - that's the only way they got here." I guess they were waiting on me to say something about it, but I just looked at them pretended that I didn't hear them and went on eating like they weren't even there.

Another 18-year-old, black male recounted a conversation with his cousin at a California school:

I talked to my cousin today ... He told me there is so much racism there at the school. ... He lives in the dorm like me. ... They have four to a room. He's the only black person in the room so every time something comes up missing, they blame my cousin because he is black and he has braids and a lot of tattoos. ... They leave little messages saying, "You stupid black boy" and stuff like "If you weren't good in sports you wouldn't be here, and if we ever catch you sleeping and not paying attention, we're going to kill you."

The young man recounting the conversation counseled his cousin to transfer schools "before something bad happens."

These examples show the various ways that white people's ideologies serve as barriers to limit the access of students of color. While legal discrimination has formally been banned; the ideology that justified historical exclusion persists despite anti-discrimination protection (Bonilla-Silva, 2003; Scheurich \& Young, 1997). These current situations are reminiscent of the historical terror campaigns enacted against people of color.

The links between historical and contemporary forms of oppression are most commonly found in the contemporary race projects that define colorblind racism (Zamudio \& Rios, 2006) and in societal symbols (Brislin, 1988). As seen in the student journals, words rooted in historical discrimination are used to denigrate minority students. Students asserting status privilege called upon words like "nigger," "beaner," "prairie nigger," "fag," and "bitch" in their journals to distance themselves from the Other. Yet students are often confused as to whether these terms are acceptable to use in reference to a friend or each other. One white male wrote:

In my mind, that term "nigga" doesn't describe race anymore, but more of a friend, confidant or way of life. My friend has called me his "nigga" before, but I just don't know how well it would be received by him.

In a similar journal entry a 31-year-old, Chicano male wrote:

After getting home from the bars, Marty and I started talking about slavery and various related issues. ... I distinctly remember asking him why he would want to propagate his demented views on racial difference. Namely, calling a Latino/Chicano friend a "beaner". . I I asked him if it would be all right to call him "cracker." He said that it wouldn't bother him.

In both cases, a historical analysis of power and social relations is absent. A derogatory term for Whites, "cracker" is understood by these students as equivalent to the derogatory terms for 
Blacks and Chicanos. Yet, historically, people of color did not own "crackers," slaughter them as savage "crackers," nor steal "cracker" land and force them into the most marginal sectors of the economy and blame their "cracker" culture for their lack of assimilation and economic success. But these things were done to people of color at the hands of Whites, and the words of oppression ("beaner," "nigger," etc.) rose out of that brutal history. Even students not intending to use these terms in an oppressive manner have little understanding of the impact these words have in supporting larger structures of inequality. A critical analysis would provide students with the tools to understand that derogatory terms have meaning outside of their immediate context.

In all fairness to students struggling with the meaning and appropriateness of derogatory words, there is no absolute consensus as to what to do with these derogatory terms. For example, critical legal scholar Randall Kennedy (2003) argues that when Blacks use the word "nigger" with each other, they are actually appropriating the meaning of the word, taking the historical baggage out of it and diffusing its power. The journal entry of a critical, white, female student in this study captures an element of this process:

I was waiting in line in the student union today to buy some lunch. Close by me were a group of black males who were talking loudly. I overheard them referring to each other playfully as "nigga." The word makes me uncomfortable, but it didn't seem to affect them in the same way. I can understand that there is a certain power to reclaiming a term that's been used to denigrate a group of people in the past. It's the same with the word "dyke" or "cunt," at least in my experience. I use the word "cunt" in a way that makes me feel kind of powerful when I say it. Being able to claim ownership over a word that has been used to hurt you before is liberating. I imagine this is similar to using "nigga" in the same way.

The author of this journal entry understands the historical base of derogatory words. She is verging on an analysis of organic experience that gives the oppressed ownership over certain words as an act of liberation.

\section{Power}

The relationship between an individual to the social context is ultimately a power relationship. The ability to set the tone, to determine who is part of the center and who is Other, exemplifies the use of power. Social constructs, such as race, class, gender, and sexuality often determine one's place within a particular institutional context. Consider the next two journal entries: A 24-year-old white female captured the following:

In my Econ class ... we were talking about other countries and what products they produce. My teacher was talking about the Japanese, but instead of using the politically correct term Japanese, he said, "Japs." I know that he didn't mean it in a racist way, but that is how I took it.

A Chicano student documented the second situation in the classroom:

The class discussion was about minority groups and leading feminist activists. [The professor] had been rambling on and had not grabbed my attention until she started talking shit about Chicanos and the Chicano Studies program. She had said that she can't believe how much money these types of 
programs get and that the Chicanos that are in the school don't even support the programs set up for them.

In both cases, the professor has the power to determine who is "centered" and who is marginalized. The very nature of oppressive forms of power allows for privileged individuals to wield it over whole groups of people. This occurs because the underlying institutional power relations function in an abstract manner to facilitate the legitimacy of the action and to further obscure the nature of power. Without incorporating an understanding of power at any level, it is difficult for students to grasp that they have power by virtue of their privilege when they too often feel powerless.

\section{DISCUSSION: TOWARD A PEDAGOGY AND PRAXIS}

Our analysis of the student journals suggests the difference that critical cultural thinking makes for our understanding of salient social concepts around race, gender, and sexuality. The majority of the students' documented observations captured a level of discourse that threatens the intellectual integrity of the university. The students' contrasting explanations for their observations were directly linked to the extent to which they developed and employed analytical tools rooted in organic, relational, historical, and power constructs central to an analysis of oppression and privilege. Our findings demonstrate the urgency to provide greater support to pedagogies, policies, and practices at the university that directly address the pervasiveness and persistence of inequality around issues of difference. One avenue of pursuit is to bring students up to a level of analysis that reflects the value of critical cultural inquiry central to the academic mission.

While many of the students documented their own interactions and that of their peers on campus, many also documented the responses of their family and anonymous community members off campus to these issues. The observational findings made by the students tell us that the social forces that undermine a spirit of critical cultural inquiry exist and are reinforced beyond the immediate academic setting. The widespread absence of the use of critical cultural thinking tools when trying to understand issues of difference reinforces an environment hostile to ideals of inclusion, which a liberal arts education purportedly fosters. Thus, we must work harder to insure that the discourse at the university is not as base as that in the streets. While as educators we have little power to impact the broader social discourse, it is our responsibility to provide students with the critical cultural tools to interpret and respond to this discourse in a thoughtful way. In essence, it is the mission of the university not only to prepare students for the world of work ahead but also to help create citizens prepared to counter the discourse of exclusion and oppression. The student data, however, suggests the difficulty and complexity of the task at hand.

As educators, our role is to provide students with life-long tools to facilitate this process as they develop their capacity for citizenship (Parker, 2003). One way of doing this is to require our students to consider the social world in a rigorous way. We can expect them to analyze the world not only from their vantage point but also from the organic experience of others. We can expect them to go beyond the individualist orientation toward developing a relational analysis of the impact of social structure on groups. We can expect them to see the weight of history all around them, in their lives and the lives of others. We can expect them to understand and identify the various manifestations of power and how it operates in their lives and the lives of others. And we 
can help them develop a better understanding of difference in a way that combats the oppression that they hear and see in the dorms, the classroom, at home, and at work.

Ultimately, as a society we need to address the structural forces that make inequality possible. We are, by nature, active beings. The questions become: On what things do we act and for what purposes? We argue that we can act in ways that actively advance and strengthen the unequal relations of power inherent in the status quo. We would also argue that lack of action advances these unequal relations of power since they have been historically set in motion to reinforce and extend existing power relations. Alternately, we could act against inequality by working to address the symptoms of unequal relations of power. At the University, this often means advancing minority perspectives and struggling for broader inclusion. Finally, we could also act in ways that focus on the causes of inequality by asking: Why are there unequal relations of power? Who benefits? and How does it manifest in social structures? From here we can work to critique and dismantle the root causes of inequality. While providing students with a critical cultural consciousness about the nature of inequality in society does not change its existence, it does arm students with the necessary tools to begin constructing actions aimed at advancing our democratic ideals.

\section{NOTES}

1. We use the term "critical cultural consciousness" as well as related terms to distinguish critical thinking about difference and diversity from more generic or general forms of critical thinking.

2. English-only instruction, changing student names to more Euro-American names, and a curriculum that denigrates the colonized group while also lifting to mythic status the colonizing group are just some examples of this deculturalizing process.

\section{REFERENCES}

Anderson, J. R. (2004). Cognitive psychology and its implications (6th ed.). New York: Worth.

Bonilla-Silva, E. (2003). Racism without racists: Color-blind racism and the persistence of racial inequality in the United States. Lanham, MD: Rowman \& Littlefield.

Brislin, R. W. (1988). Prejudice in intercultural communication. In L. A. Samovar \& R. E. Porter (Eds.), Intercultural communication: A reader (5th ed., pp. 339-343). Belmont, CA: Wadsworth.

Darder, A. (2002). Reinventing Paulo Freire: A pedagogy of love. Boulder, CO: Westview.

Feagin, J. R., \& Feagin, C. B. (1986). Discrimination American style: Institutional racism and sexism (2nd ed.). Malabar, FL: Kreuger.

Freire, P. (1970/1998). Pedagogy of the oppressed. New York: Continuum.

Freire, P. (1973). Education for critical consciousness. New York: Seabury.

Freire, P. (1985). The politics of education: Culture, power and liberation. South Hadley, MA: Bergin \& Garvey.

Freire, P. (1998). Teachers as cultural workers: Letters to those who dare to teach (D. Macedo, D. Kolke, \& A. Oliveira, trans.). Boulder, CO: Westview.

Giroux, H. (1985). Introduction. In P. Freire, The politics of education: Culture, power and liberation (pp. xi-xxv). South Hadley, MA: Bergin \& Garvey.

Gruwell, E. (1999). The freedom writers' diary: How a teacher and 150 teens used writing to change themselves and the world around them. New York: Broadway Books.

Horton, A. I. (1989). The Highlander Folk School: A history of its major programs. New York: Carlson.

Kennedy, R. (2003). Nigger: The strange career of a troublesome word. New York. Vintage Books.

McIntosh, P. (1990). White privilege: Unpacking the invisible knapsack. IndependentSchools, 49(2), 31-36. 
McLaren, P. (2000). Che Guevara, Paolo Freire, and the pedagogy of revolution. Lanham, MD: Rowman \& Littlefield.

McLaren, P. (2003). Critical pedagogy: A look at the major concepts. In A. Darder, M. Baltodano, \& R. Torres (Eds.), The critical pedagogy reader (pp. 68-96). New York: RoutledgeFalmer.

Moll, L. C., Amanti, C., Neff, D., \& Gonzalez, N. (1992). Funds of knowledge for teaching: Using a qualitative approach to connecting homes and classrooms. Theory into Practice, 31(2), 132-142.

Montoya, M. (1998). Masks and acculturation. In R. Delgado \& J. Stefancic (Eds.), The Latina/o condition: A critical reader (pp. 276-283). New York: New York University Press.

Parker, W. (2003). Teaching democracy. New York: Teachers College Press.

Payne, R. (2005). A framework for understanding poverty. Highlands, TX: Aha Process.

Scheurich, J. J., \& Young, M. (1997). Coloring epistemologies. Educational Researcher, 26(4), 4-16

Shor, I., \& Pari, C. (Eds.) (2000). Education is politics: Critical teaching across differences, postsecondary. Portsmouth, NH: Boyton/Cook

Skinner, B. F. (2002). Beyond freedom and dignity (Rev. ed.). Indianapolis, IN: Hackett.

Springs, J. H. (2003). Deculturalization and the struggle for equality: A brief history of the education of dominated cultures in the U.S. (4th ed.). New York: McGraw-Hill.

Steinberg, S. (1989). The ethnic myth: Race, ethnicity, and class in America. Boston: Beacon Press.

Strauss, A., \& Corbin, J. (1998). Basics of qualitative research: Techniques and procedures for developing grounded theory (2nd ed.). Thousand Oaks, CA: Sage.

Trent, A., Rios, F., Antell, J., Berube, W., Bialostok, S., Cardona, D., Paradis, E., \& Rush, T. (2003). Problems and possibilities in the pursuit of diversity: An institutional analysis. Equity and Excellence in Education, 36(3), $213-224$.

University academic plan. (2004). University of Wyoming. Laramie: Author.

VanDeventer Iverson, S. (2007). Camouflaging power and privilege: A critical race analysis of university diversity policies. Educational Administrational Quarterly, 43(5), 586-611.

Villenueva, V. (1993). Bootstraps: From an American academic of color. Urbana, IL: National Council of Teachers of English.

Vygotsky, L. S. (1980). Mind in society. Cambridge, MA: Harvard University Press

Weiner, L. (2000). Research in the 90s: Implications for teacher preparation, Review of Educational Research, 70(3), 369-406.

Westheimer, J., \& Kahne, J. (2004). What kind of citizen? The politics of educating for democracy. American Educational Research Journal, 41(2), 237-269.

Zamudio, M., \& Rios, F. (2006). From traditional to liberal racism: Living racism in the everyday, Sociological Perspectives, 49(4), 483-501.

Margaret Zamudio is an assistant professor in the Department of Sociology at the University of Wyoming. Her research focuses on issues of race, class, and gender, critical race theory, immigration, and labor.

Francisco Rios is a professor in the Education Studies department at the College of Education at the University of Wyoming. His research interests include teachers of color, Latinos in education, and preservice teacher education with a multicultural focus.

Angela M. Jaime is an assistant professor in the Department of Educational Studies, College of Education at the University of Wyoming. Angela specializes in the research of American Indian education, women's studies, diversity, and multicultural education. 